\title{
Pharmacological Study on Activity of Silymarin and/or Zinc Oxide Nanoparticles against Hepatic Dysfunction Using Cell Line HepG2
}

\section{Sameh S Gad*}

Lecturer of Pharmacology and Toxicology, Faculty of Pharmacy, October University for Modern Science and Arts (MSA), Egypt

*Corresponding author: Sameh S Gad, Lecturer of Pharmacology and Toxicology, Faculty of Pharmacy, MSA University, Cairo, Egypt, Tel: 01207355765; Email: sameh.shaaban@msa.eun.eg

\section{Research article}

Volume 3 Issue 3

Received Date: July 11, 2019

Published Date: August 09, 2019

DOI: $10.23880 /$ vij-16000218

\section{Abstract}

Introduction: The liver is the primary organ for metabolism. The increase of use in nanoparticles nowadays is scary to such an important organ unless it is fully investigated. Therefore, our aim is evaluating the hepatoprotective effect of silymarin in alone and in combination with zinc oxide nanoparticles Zno NPs against hepatic dysfunction induced by methotrexate (MTX) on human liver cells (HepG2). Methotrexate is an anti-metabolite that is used in treating autoimmune illness and cancer but it induces liver toxicity so that its application is limited.

Methods and Results: In our study, we investigated the hepatoprotective effect of Zno NPs, and silymarin against HepG2 cells induced by (MTX). Doses were determined according to determination of the IC50 for each compound, dose of induction used was $75 \mu \mathrm{g} / \mathrm{ml}$ of methotrexate. Results showed that Zno NPs with silymarin exert a distinct effect on cells viability by causing a great hepatoprotection for Hep G cells. We used different doses for both silymarin and Zno NPs. Doses used for silymarin were (100, 75 and $50 \mu \mathrm{g} / \mathrm{ml})$, and doses of Zno NPs were $(20,10$ and $5 \mu \mathrm{g} / \mathrm{ml})$, but actually the most hepatoprotective doses exerted by Zno NPs and silymarin were 10 and $50 \mu \mathrm{g} / \mathrm{ml}$ which achieved about 97\% cell viability.

Conclusion: Overall, our data demonstrated that Zno NPs in combination with silymarin cause a hepatoprotection for Hep G2 cells pretreated with methotrexate to cause liver cytotoxicity. This study provides guidance for development of treatment of liver dysfunction using this combination of Zno NPs and silymarin. in addition, this study suggests that further investigation required for better understanding of nanoparticles use.

Keywords: Zno NPs; Silymarin; MTX; Hep G2 cells; MTT assay 


\section{Virology \& Immunology Journal}

Abbreviations: EU: European Union; ROS: Reactive Oxygen Species; GPx: Glutathione Peroxidase; SOD: Superoxide Dismutase; GGT: Glutamyl Transferase; AST: Aspartate Aminotransferase SOD: Super Oxide Dismutase; FDA: Food and Drug Administration.

\section{Introduction}

The major and very important structure and secretary organ in the human body is the liver, it weighs about 34Ibs. It's located in the upper right of abdominal cavity and resting on stomach, abdominal cavity, right kidney, and colon [1].

\section{Epidemiology}

Liver disease is very critical and spread widely around the world. In 2013, about 29 million of people in the European Union (EU) were suffering from a chronic liver disease.

According to Around30 million people in the USA have liver disease - which means 1 in 10 Americans. Cirrhosis is a very late stage of liver disease [2,3]. It occurs when normal tissues of the liver are replaced by scar tissue and in this case it's called fibrosis. Globally, liver cirrhosis was estimated to be the reason for death of over million people in 2010, which represent $2 \%$ of all deaths around the world. Cirrhosis was the main cause of adult liver transplantation in Europe with 57,529 carried out between 1988 and 2013 [4].

Liver diseases include hepatitis, liver injury, alcohol related disorders cirrhosis, and liver cancer. This exposure to different environmental pollutants, and xenobiotic such as paracetamol, alcohol, methotrexate, carbon tetrachloride, and carbofuran causes damage of the liver by production of reactive oxygen species (ROS), these free radicals are responsible for induction of hepatotoxicity by covalent binding to tissues of the liver. Also, these free radicals may decrease immunity and lead to many other diseases. Removal of free radicals by antioxidants will help in reduction of fibrosis of liver tissues [5].

Many natural agents are discovered to be with medicinal benefits such as natural agents with hepatoprotective activity. These agents can protect liver as it contains a lot of bioactive molecules, but these molecules to be identified require a very careful selection and execution of bioassays during research process. In vitro techniques are very important way in the evaluation of natural products with hepatoprotective effects [6]. Medicinal natural agents which are known by its hepatoprotective effect such as curcumin, silymarin, Licorice, Rhein, Resveratrol, and Rutin.

\section{Silymarin}

Silymarin is a natural plant which obtained from the seeds of Silybummarianum (milk thistle).This plant has been used since the ancient times in the medical field to protect and treat several liver diseases. Also, it is used widely and it is found in prescriptions of herbalists as it has almost no side effects. The native place to silymarin plant is the Mediterranean and it grows in different places around the world especially in Europe, North America, India, China, South America, Africa and Australia. Silybinin is one of silymarin structural components. Not only silymarin, but also silybin (silybinin) have been documented with great hepatoprotective activities, because it's discovered that these substances have a very effective role in treatment of various liver diseases such as acute and chronic viral hepatitis, toxins which induce hepatic injury or diseases, types of drugs-induced hepatitis, cirrhosis and alcoholic liver diseases. It has an effective role in restoring liver function and regeneration of cells of the liver. Silymarin antagonizes the toxin called (alpha-aminitine) of Amanita phalloides and has a protective role against toxicity caused by many substances such as carbon tetrachloride, phalloidine, galactosamine, paracetamol, thioacetamide and halothane. Silymarin also has an effective role in protection of the hepatocytes from any injury caused by poisoning, iron overload, ischemia, radiation, and viral hepatitis, so if we search into the pharmacopoeia of a lot of countries, this plant will be included in and it is found also to be used as supportive therapy in food poisoning by fungi and in patients with chronic liver disorders such as steatosis and alcohol-liver disease. It is also effective in certain types of cancers $[7,8]$.

Silymarin has beneficial effect on different types of chronic disorders such as cancer, oxidative stress and congestions of spleen, dyspepsia and diabetes in addition to liver, kidney, inflammatory, GIT disorders. It improves liver injury induced by drugs such as carbon tetrachloride, arsenic or acetaminophen. So that it has potential anti-hepatotoxic property as it blocks toxins binding sites. In case of liver damaged by ethanol, silymarin can restore its function by its antioxidant and hepatoprotective properties in addition to its ability to reduce liver markers in case of alcoholic liver cirrhosis and hepatitis. Silymarin has potential effect on liver fibrosis condition by decreasing stellate cells conversion 


\section{Virology \& Immunology Journal}

into myofibroblastes. It isn't only acts on the cell membrane but also acts on the nucleus for increasing ribosomes and DNA synthesis that resulting in synthesis of protein by RNA polymerase I stimulation. It is very important step cellular injury repairing and it is important to restore protein and enzymes structures that damaged by toxins effects [9].

As a hepatoprotective drug, silymarin has various mechanisms of actions against many hepatotoxic agents. The antioxidant activity and cell regenerating functions as a result of increasing the synthesis of the protein .This plant act by inhibiting the hepatotoxin binding to receptor sites on the hepatocyte membrane; by reducing the glutathione (GSH) oxidation to increase its level in the liver; and also causes stimulation of the ribosomal RNA polymerase and subsequent protein synthesis which will lead to increase the ability of hepatocyte to be regenerated. One of the mechanisms shows the capability of silymarin to stimulate liver tissue regeneration through increasing protein synthesis in the injured liver.

In in vivo and in vitro experiments that performed in liver of rats, silybinin causes an increase in the formation of ribosomes and synthesis of both DNA and protein. Silymarin inhibits the hepatic cytochrome P450 detoxification system. Silymarin can be orally absorbed but unfortunately it has very poor bioavailability due to its poor water solubility. Furthermore, silymarin and its main component silybinin are used for protection human's liver. Silymarin shows great hepatoprotection in different toxic experimental models in laboratory animals due to its multiple properties such as anti- oxidative, antiinflammatory, anti-fibrotic, anti-lipid peroxidative, membrane stabilizing and liver regenerating properties. Medicinal uses of silymarin for humans include treatment of alcoholic liver diseases, viral hepatitis, liver cirrhosis, and toxic and drug-induced liver diseases [10]. Silymarin protects rat liver mitochondria and microsomes in vitro against specific injury and toxicity induced by paracetamol. Recognition of derivatives of silymarin opens new ways for its application in treatment of liver disorders.

\section{Zinc Oxide Nanoparticles}

One of the most abundant Nano materials used in cosmetics and sun screens due to their efficacy to absorb UV light in addition to they prevent visible light from scattering is Zinc oxide nanoparticles (Zno NPs). So that Zno NPs are more transparent and aesthetical agreeable when compared to its bulk form. It used in industry as food additives and used in packaging as they have antimicrobial characterizes. Also, they have antifungal properties in agriculture in addition to they can be used as anticancer drugs. Since direct human exposure to Zno NPs so logically the liver is the major target organ after their entry to the body through any one of the possible routes. As some existing studies of Zno NPs toxicity showed that its molecular mechanism still largely unclear. Some studies explored Zno NPs side effects in human liver as it is primary organ for metabolism. And other studies showed their accumulation into the liver when given orally and leading to liver damage. Another study administrated radiolabelled functionalized fullerenes intravenously of rats and the major content founded and retained in the liver [11].

The study aims to investigate the effect of Zno NPs on HepG2 of human liver cells trying to understand its mechanism by assaying lipid peroxidation, ROS generation and oxidative DNA damage in addition to apoptosis [11]. HepG2 cell line was used as the hepatocellular carcinoma was one of the largest health problems as it accounts yearly for more than 626000 new cases around the world. This type extensively used for developing new anticancer drugs that considered as human liver model [12].

HepG2 is highly differentiated and present many genotypic types of normal liver cells. These cells can be used for screening potential of the cytotoxicity of new drugs during phase of lead generation. But, their main disadvantages due to their low metabolic capacity compared to primary hepatocytes that make them very suitable for toxicity testing of the parent molecule but less appropriate for testing metabolite toxicity. They have low cytochromes levels but have normal levels of phase II enzymes excluded UDP-glucuronosyl transferases.

Recently ZnO NPs have received much attention for their great effect in treatment of cancer .Studies showed that ZnO NPs induce cytotoxicity in cells, so ZnO NPs will lead to death of rapidly dividing cancer cells [12]. The mechanism of toxicity of ZnO NPs is not understood, but there are some components that generated from the surface of zinc oxide nanoparticles such as superoxide anions, hydroxyl radicals, and per hydroxyl radicals which may be the main reason for this toxicity. In fact when zinc oxide nanoparticles react with cells, these components will be generated, and the cellular protection mechanism will be activated as a defense mechanism to decrease the harmful effect. However, if the generation of free radicals exceeds the defensive mechanism of the cells, this will lead to oxidative harm which will cause death of the cells 


\section{Virology \& Immunology Journal}

[13]. Toxicity of $\mathrm{ZnO}$ NPs was evaluated in variant biological systems eg: bacteria mammalian cells and also in vivo models .The toxic effect of zinc oxide nanoparticles in mammalian cells will appear as a membrane injury, inflammatory response, damage of the DNA and apoptosis [11]. Chemotherapy is one of systemic treatment for cancer diseases. It helps to treat patients with cancer diseases, but unfortunately it damages not only cancer cells, but also it cause damage of normal and unaffected tissues, organs, and cells, and this is actually the major problem of chemotherapy treatment. In recent times, nanomedicine is the best choice for treatment of such diseases. Although zinc is safe and important trace element in the cells, but actually if its concentration increases inside the cells it will lead to death of these cells. ZnO NPs was found to be very toxic to cancer in vitro cells, with less effect on normal cells which will be very useful in treatment of cancer [14].

Nowadays Nanotechnology has a good deal with controlling, modifying and fabricating materials/ structures and also devices with precision of nano-meter. Also it is help to realizing the basics of physics, chemistry, biology and technology of the objects of nanoparticls metrescale. So, Zn oxide nanoparticles are nano-particles its size less than $100 \mathrm{~nm}$, several of different methods to prepare Nanoparticles such as solid, liquid and also gaseous [15]. There are variance of the chemical methods that can be used also such as: mechano-chemical process, precipitation Process by using surfactant, also sol-gel method, And finally the micro emulsion methods we use The chemical methods because these methods are costeffective, very reliable and friendly with environment and also being flexible to control the size and shape of nanoparticles synthesis. Nanoparticles should be stable so that we preferred the high of surface area: volume ratio. So, these properties of this novel are mainly responsible for the unique and special application of nanoparticles in both biological and also medical field. Recently Zinc oxide NPs have a wide range in cancer therapy applications. Zn oxide widely researched for their properties for anticancer thereby. So, the features of ZnO NPs are shown relatively high biocompatibility, also in in vitro model $\mathrm{ZnO}$ NPS showing a good selective cytotoxicity against cancer cells compared with other NPs, easy to synthesis the ZnO NPs, ZnO show enhanced Cytotoxicity because of their biocompatibility through zinc-mediated protein activity [16]. ZnO NPs have very unique ability to induce Oxidative Stress in cancerous cells, which is one of the mechanisms of cytotoxicity of ZnO NPs towards cancer cells.

\section{Methotrexate (MTX)}

It is a folic acid blocker, and it is versatile drug which is used widely for treatment of many diseases such as multiple sclerosis, dermatomyositis, psoriasis, systemic lupus erythematosus, sarcoidosis, and also in several inflammatory diseases. Also, it is actually used in treatment of many cancer diseases, but in high doses. However, the cytotoxic effect of MTX is not selective for cancer cells only, it also affects the normal cells and tissues and prolonged exposure or use of it will lead to cytotoxicity of the cells. In fact, the therapeutic applications of this drug are limited due to its several side effects and also severe toxicity to the liver. The mechanism of hepatotoxicity of MTX has not been fully identified, however, several studies proposed that this toxicity occurs due to the excessive generation of reactive oxygen and nitrogen species (ROS/RNS).This will promote the development of hepatotoxicity. Mitochondria are considered the primary target for oxidative stress. However, there are many scavenger systems like superoxide dismutase (SOD), glutathione peroxidase (GPx), catalase and glutathione $S$ transferase (GST), which act to remove reactive oxygen species (ROS) and maintain the normal function of mitochondria. MTX has an indirect role in liver mitochondria damage. This damage occurs through the depletion of enzymatic and non-enzymatic mitochondrial antioxidants [17].

Another mechanism for liver toxicity by MTX is the depletion of folate stores. The relationship between depletion of folate and liver toxicity has not been identified well yet. However, in case of in vivo treatment with MTX, supplementation with folic acid $1 \mathrm{mg}$ per day or folinic acid $2.5 \mathrm{mg}$ per week was found to be effective and useful in decreasing the incidence of aminotransferases elevation, and occurrence of hepatotoxicity [18]. MTX also will lead to increase the elevation in levels of hepatic transaminase. Also, many changes occur in liver histology, and lead to liver damage and problems such as: fibrosis and cirrhosis [19].

It is used widely as a disease modifying anti rheumatic medicine because of its efficacy and also cost is low and more familiar to physicians. As we know there is no benefits without occurring of adverse effects so, MTX has known toxicity profile that makes obviously toxicity in liver and induced it. So the association between MTX and hepatotoxicity or dysfunction of the liver according to the doses used in disorders whatever low doses in rheumatoid arthritis or high doses in cancer cases has been most extensively studied. MTX cause the levels of the transaminase elevated apparently in liver as it well- 


\section{Virology \& Immunology Journal}

defined. So, it is makes changes in liver especially such as: fibrosis and cirrhosis [20].

\section{Material and Methods}

\section{HepG-2 Cell Culture}

Cells were cultured in tissue culture flasks and maintained in RPMI medium supplemented with $10 \%$ fetal bovine serum, $2 \mu \mathrm{mol} / \mathrm{ml}$ L-glutamine, $250 \mathrm{ng} / \mathrm{ml}$ fungi zone, 100 units $/ \mathrm{ml}$ penicillin $\mathrm{G}$ sodium, and 100 units $/ \mathrm{ml}$ streptomycin sulphate at $37^{\circ} \mathrm{C}$ in a humidified $5 \% \mathrm{CO}_{2}$ incubator (Model: HF 1600, and Shanghi Lishen Scientific Co., Shanghai, China). The cultures were passaged every four days by trypsinization using $1 \mathrm{ml}$ trypsin/EDTA solution for 5 min at $37^{\circ} \mathrm{C}$. Cells were used when confluence had reached $75 \%$.

Trypsin/EDTA solution consists of $0.25 \mathrm{mM}$ trypsin and $1 \mathrm{mM}$ EDTA dissolved in phosphate buffer.

Preparation of Cell Lysates: After cells treatment as previously mentioned in the experimental design, cells were trypsinized, washed and centrifuged for $10 \mathrm{~min}$ at $1000 \times$ g. Cell pellets were lysed in $0.5 \mathrm{ml}$ of ice-cold lysis buffer. This buffer consists of $50 \mathrm{mM}$ Tris $\mathrm{HCl}, 150 \mathrm{mM}$ $\mathrm{NaCl}, 1 \mathrm{mM}$ EGTA, $1 \mathrm{mM}$ EDTA, 20mM NaF, $100 \mathrm{mM}$ Na3V04, $0.5 \% \quad$ NP40, $1 \%$ Triton X-100, $1 \mathrm{mM}$ phenylmethylsulfonyl fluoride, $10 \mathrm{mg} / \mathrm{ml}$ aprotinin, and $10 \mathrm{mg} / \mathrm{ml}$ leupeptin ( $\mathrm{pH}$ 7.4). Cell lysates were passed through a 21-gauge needle to break up cell aggregates, and then centrifuged at $14,000 \mathrm{xg}$ for $15 \mathrm{~min}$ at $4^{\circ} \mathrm{C}$.

MTT Cell Proliferation Assay: MTT assay is the most commonly used viability assay and it was first described by Tim Mosmann in 1983. This assay is done in order to determine the proper doses of each drug used in this study as well as to evaluate the protective effects of the hepatoprotective effects of silymarin and nano-zinc against methotrexate induced cytotoxicity in HepG2 cells (Figures 1\&2).

Calculations: The percentage of relative viability was calculated using the following equation: [Absorbance of treated cells/ Absorbance of control cells)] X 100.

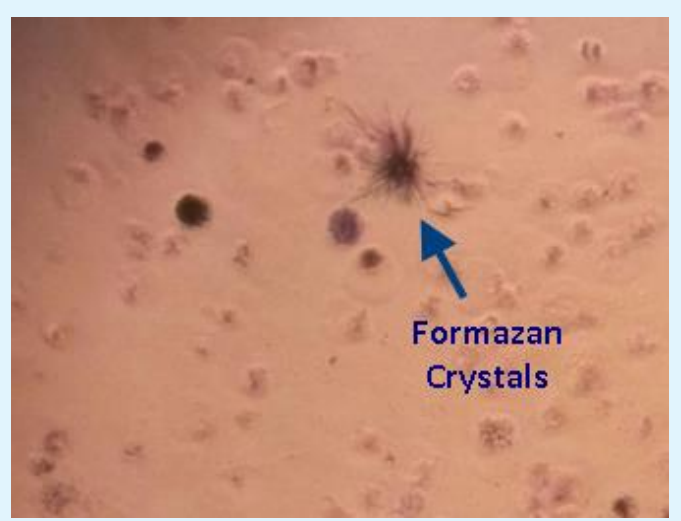

Figure 1: Formazan crystals formation after MTT addition

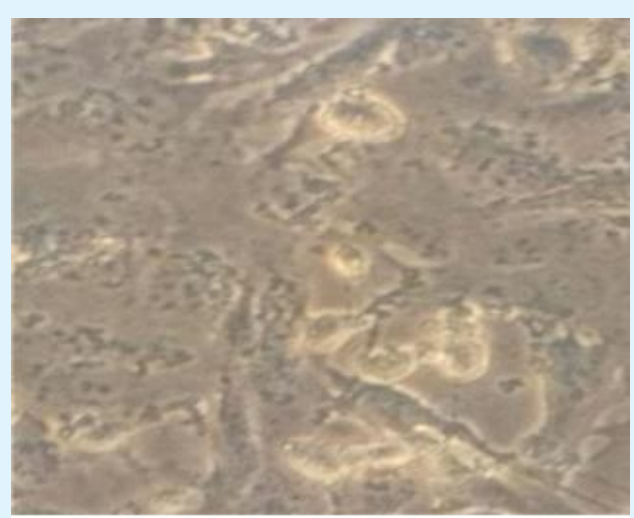

Figure 2: HepG2 Cells.

Determination of lipid peroxides: Lipid peroxidation was determined as a marker for oxidative stress. It was indirectly quantified by estimating the level of thiobarbituric reactive substances (TBARS) that were measured as malondialdehyde (MDA). The latter is a decomposition product of the process of lipid peroxidation and it was measured using a colorimetric assay kit (Biodiagnostic, Cairo, Egypt) according to the method of Ohkawa, et al. (Figure 3).

Calculation: Lipid peroxides in tested samples were determined using the standard curve and expressed as $\mathrm{nM} / \mathrm{mg}$ protein.

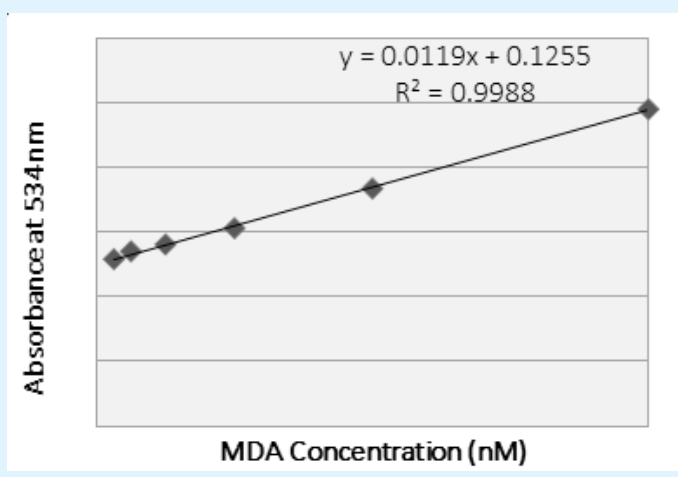

Figure 3: Standard Calibration curve for MDA. 
Estimation of the reduced glutathione content: Glutathione Content was estimated according to the method described by Tietze (1969) (Figure 4).

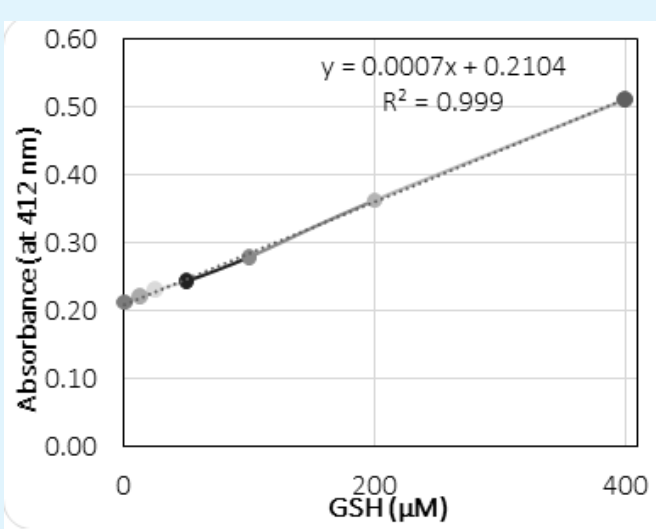

Figure 4: Standard calibration curve for GSH.

\section{Virology \& Immunology Journal}

Calculations: The GSH level was calculated using the standard curve and expressed as $\mu \mathrm{M} / \mathrm{ml}$.

\section{Results}

\section{Cell Viability Assay}

The $\mathrm{IC}_{50}$ Value for Methotrexate, Silymarin and Zinc Nano-Formulation: As shown in the following table the $\mathrm{IC}_{50}$ values were estimated for each drug on HepG-2 cells to estimate the proper doses for nano zinc and silymarin that would be used to evaluate their hepatoprotective effect against methotrexate (Table 1) (Figure 6).

\begin{tabular}{|c|c|c|c|}
\hline Drug & Methotrexate & Silymarin & Zinc nano-formulatiom \\
\hline $\mathrm{IC}_{50}(\mu \mathrm{g} / \mathrm{ml})$ & 80.2 & 270.7 & 93.4 \\
\hline
\end{tabular}

Table1: $\mathrm{IC}_{50}$ value for methotrexate, silymarin and zinc nano-formulation.
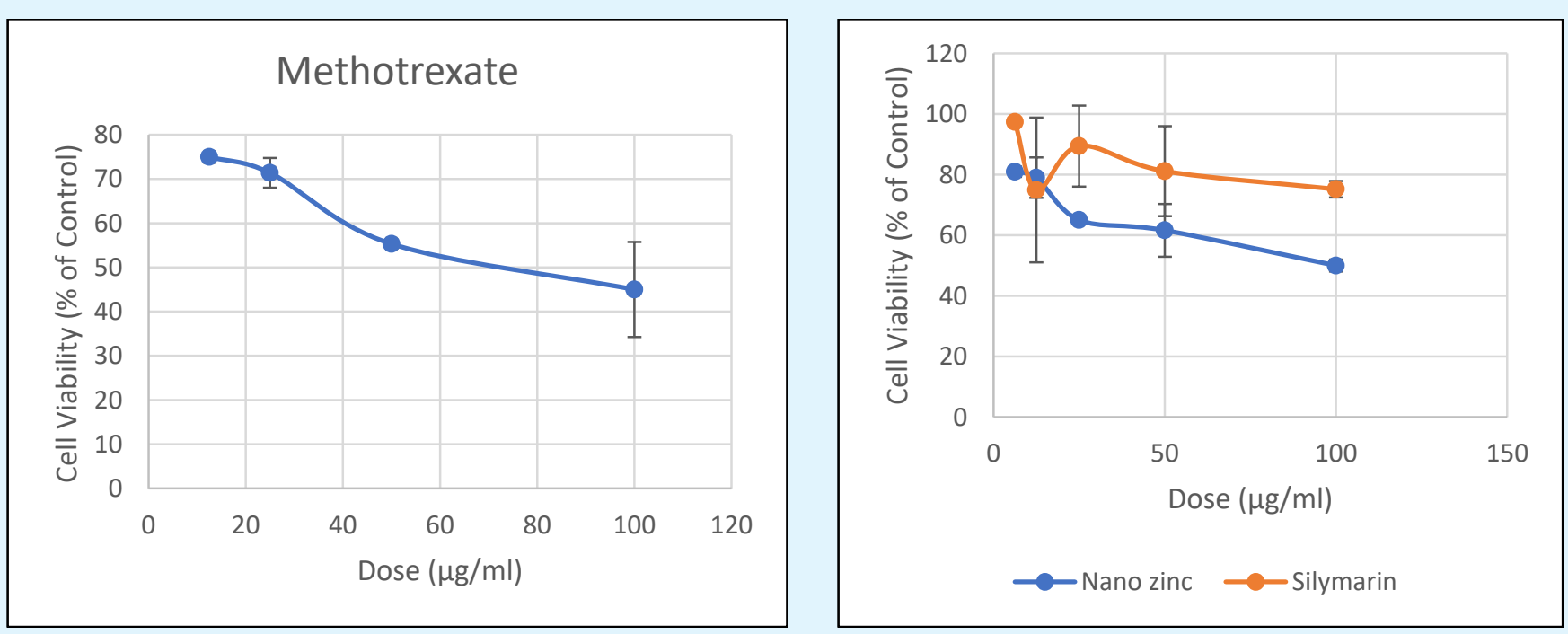

Figure 6: Cell viability in case of methotrexate, Nano zinc and silymarin.

The Hepatoprotective Effect of Silymarin or Nano-Zinc against Methotrexate: As shown in the figure three doses were selected according to the previous dose cellviability curve for silymarin $(100,75$ and $50 \mu \mathrm{g} / \mathrm{ml})$ and nano zinc $(20,10$ and $5 \mu \mathrm{g} / \mathrm{ml})$ to evaluate their hepatoprotective effect against methotrexate $75 \mu \mathrm{g} / \mathrm{ml}$. The most hepatoprotective doses exerted by nano zinc and silymarin were 5 and $50 \mu \mathrm{g} / \mathrm{ml}$ respectively and their combinations also provided protective effects against methotrexate (Figure 7). 


\section{Virology \& Immunology Journal}

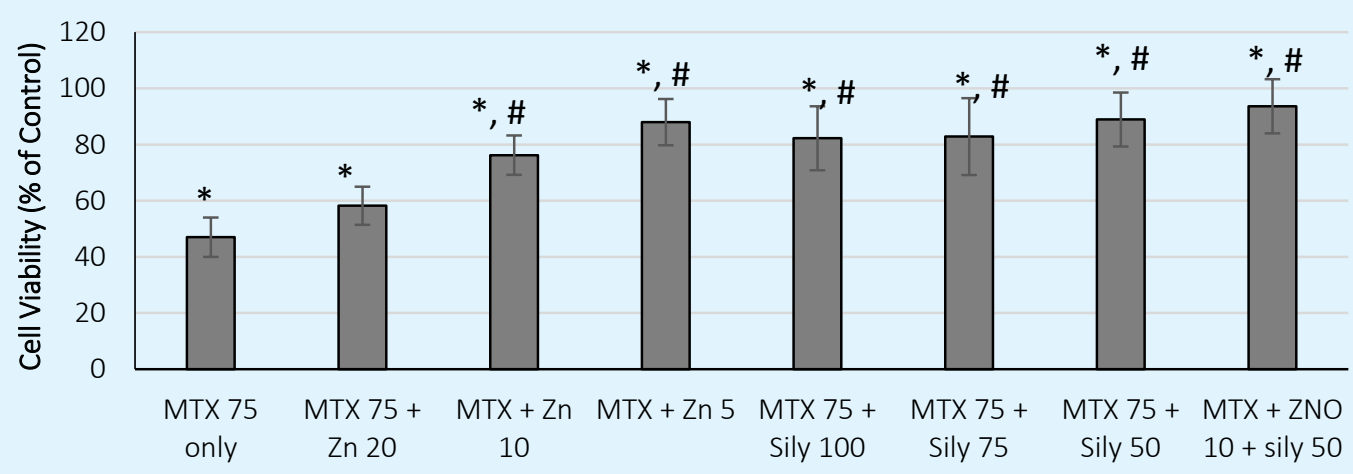

Figure 7: Hepatoprotective effect of silymarin or nano-zinc against methotrexate.

The effect of different concentrations of silymarin $(100,75 \& 50 \mu \mathrm{g} / \mathrm{ml})$ as well as different concentrations of Nano-zinc $(20,10 \& 5 \mu \mathrm{g} / \mathrm{ml})$ on cell viability and their protective effect against cytotoxicity induced by methotrexate $(75 \mu \mathrm{g} / \mathrm{ml})$ in HepG-2 cells after $24 \mathrm{~h}$ incubation time. Data were expressed as the mean \pm S.D as compared to control cells. Statistical analysis was carried out using one-way ANOVA, followed by Tukeykramer's multiple comparison tests.

* Significantly different from control group at $\mathrm{p}<0.05$. \# Significantly different from Methotrexate group at $\mathrm{p}<$ 0.05 .

\section{Lipid Peroxides}

Both of Silymarin and Nano-zinc as well as their combination significantly protected HepG2 cells from methotrexate induced lipid peroxidation and increased MDA levels (Table 2).

\begin{tabular}{|c|c|}
\hline Group & MDA $(\boldsymbol{\mu M} / \mathbf{m l})$ \\
\hline Control & $0.69 \pm 0.17$ \\
\hline Methotrexate $(75 \mu \mathrm{g} / \mathrm{ml})$ & $1.43 \pm 0.11^{*}$ \\
\hline Methotrexate + Silymarin & $0.96 \pm 0.24^{\#}$ \\
\hline Methotrexate + Nano-Zinc & $1.01 \pm 0.17^{* \#}$ \\
\hline $\begin{array}{c}\text { Methotrexate + Silymarin + } \\
\text { Silymarin }\end{array}$ & $0.90 \pm 0.18^{\#}$ \\
\hline
\end{tabular}

Table 2: The protective effect of silymarin and/or nanozinc against methotrexate induced lipid peroxidation in HepG-2 cells.

The protective effect of silymarin is $(50 \mu \mathrm{g} / \mathrm{ml})$ alone or in addition of Nano-zinc $(5 \mu \mathrm{g} / \mathrm{ml})$ on MDA level induced by methotrexate $(75 \mu \mathrm{g} / \mathrm{ml})$ in HepG-2 cells after $24 \mathrm{~h}$ incubation time. Data were expressed as the mean \pm S.D as compared to control cells. Statistical analysis was carried out using one-way ANOVA, followed by Tukeykramer's multiple comparison tests.

* Significantly different from control group at $\mathrm{p}<0.05$. \# Significantly different from Methotrexate group at $\mathrm{p}<$ 0.05 (Figure 8).

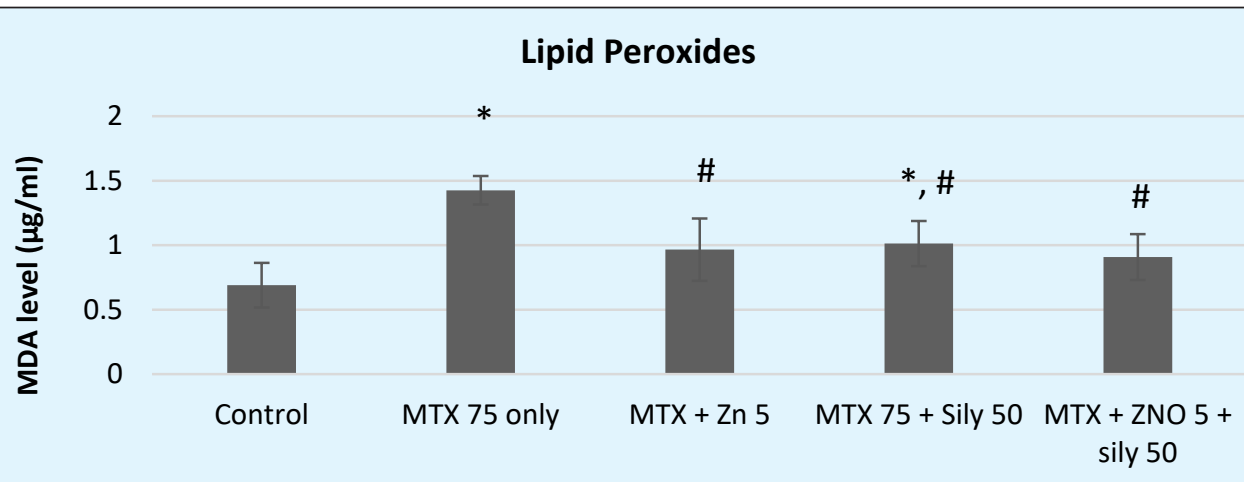

Figure 8: The protective effect of silymarin and/or nano-zinc against methotrexate induced lipid peroxidation in HepG-2 cells. 
The protective effect of silymarin is $(50 \mu \mathrm{g} / \mathrm{ml})$ alone or in addition of Nano-zinc $(5 \mu \mathrm{g} / \mathrm{ml})$ on MDA level induced by methotrexate $(75 \mu \mathrm{g} / \mathrm{ml})$ in HepG-2 cells after $24 \mathrm{~h}$ incubation time. Data were expressed as the mean \pm S.D as compared to control cells. Statistical analysis was carried out using one-way ANOVA, followed by Tukeykramer's multiple comparison tests.

* Significantly different from control group at $p<0.05$.

\# Significantly different from Methotrexate group at $\mathrm{p}<$ 0.05 .

\section{Reduced Glutathione Content (GSH)}

Both of Silymarin and Nano-zinc as well as their combination significantly protected HepG2 cells from methotrexate induced hepatotoxicity as they restored GSH levels depleted by methotrexate (Table 3).

The protective effect of silymarin $(50 \mu \mathrm{g} / \mathrm{ml})$ alone or in addition of Nano-zinc $(5 \mu \mathrm{g} / \mathrm{ml})$ aginst induced by methotrexate $(75 \mu \mathrm{g} / \mathrm{ml})$ induced hepatotoxicity in HepG-

\section{Virology \& Immunology Journal}

2 cells and their effect on GSH level after $24 \mathrm{~h}$ incubation time.

\begin{tabular}{|c|c|}
\hline Group & GSH $(\boldsymbol{\mu M} / \mathbf{m l})$ \\
\hline Control & $58.7 \pm 1.7$ \\
\hline Methotrexate $(75 \mu \mathrm{g} / \mathrm{ml})$ & $34.6 \pm 4.2^{*}$ \\
\hline Methotrexate + Silymarin & $40.4 \pm 3.8^{*}$ \\
\hline Methotrexate + Nano-Zinc & $44.6 \pm 0.67^{* \#}$ \\
\hline $\begin{array}{c}\text { Methotrexate + Silymarin + } \\
\text { Silymarin }\end{array}$ & $51.3 \pm 5.3^{* \#}$ \\
\hline
\end{tabular}

Table 3: The hepatprotective effect of silymarin and/or nano-zinc against methotrexate and the effects on GSH level in HepG-2 cells.

Data were expressed as the mean \pm S.D as compared to control cells. Statistical analysis was carried out using one-way ANOVA, followed by Tukey-kramer's multiple comparison tests.

* Significantly different from control group at $p<0.05$.

\# Significantly different from Methotrexate group at $\mathrm{p}<$ 0.05 (Figure 9).

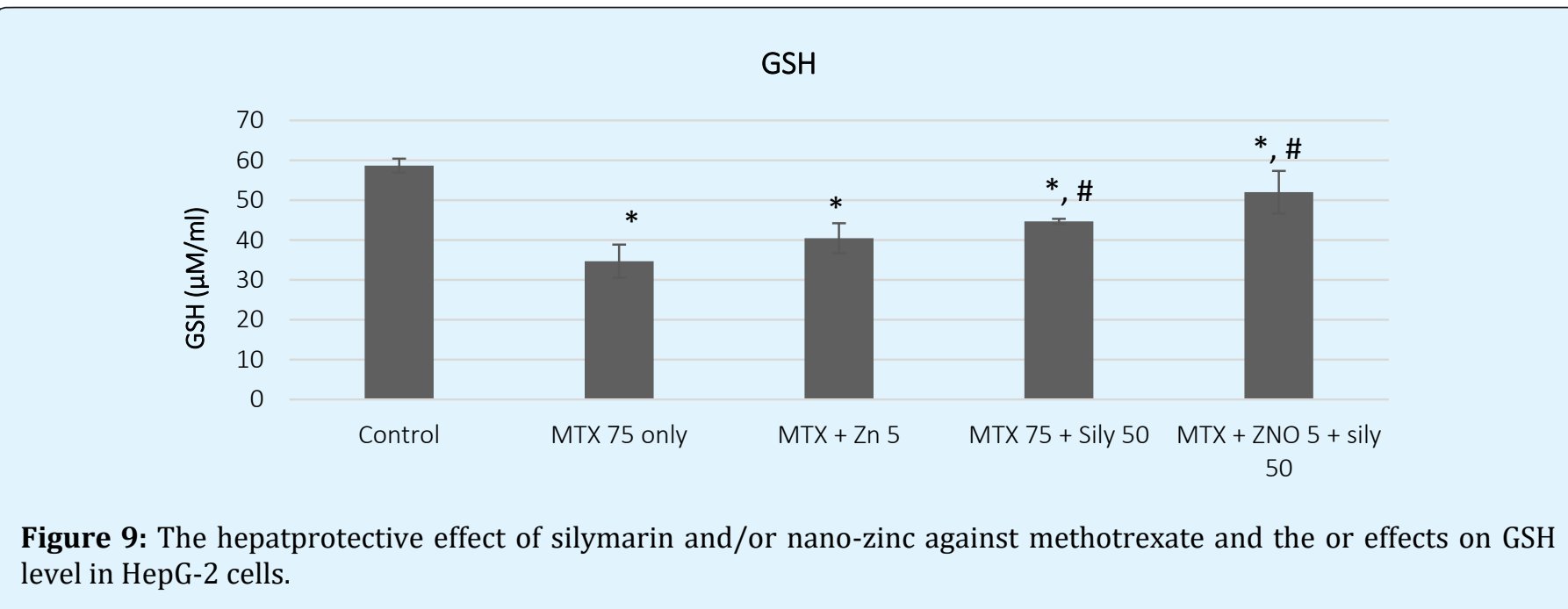

The protective effect of silymarin $(50 \mu \mathrm{g} / \mathrm{ml})$ alone or in addition of Nano-zinc $(5 \mu \mathrm{g} / \mathrm{ml})$ against induced by methotrexate $(75 \mu \mathrm{g} / \mathrm{ml})$ induced hepatotoxicity in HepG2 cells and their effect on GSH level after $24 \mathrm{~h}$ incubation time. Data were expressed as the mean \pm S.D as compared to control cells. Statistical analysis was carried out using one-way ANOVA, followed by Tukey-kramer's multiple comparison tests.

* Significantly different from control group at $p<0.05$. \# Significantly different from Methotrexate group at $\mathrm{p}<$ 0.05 .

\section{Discussion}

Some studies revealed that silymarin doses of 250 to $500 \mathrm{mg} / \mathrm{ml}$ lead to hepatoprotective effect. It has been reported that hepatocytes that received silymarin in combination with other compounds or alone will reduce liver enzymes activity and specifically acetaminophen that induced liver toxicity in mice cell line because of its ability to decrease the free radical induced oxidative damage in the liver and also help to improve the 
antioxidant status in the liver during acetaminophen hepatotoxicity.

In another previous studies, they pretreated HepG2 cells with silymarin because it's as a hepatoprotective agent .They used different doses of silymarin 10 and 100 $\mu \mathrm{g} / \mathrm{mL}$ respectively and then exposure of cells to carbon tetra chloride was done to induce damage, but it can't prevent the total antioxidant capacity compared with Carbon tetra chloride that Pretreated with silymarin alone without any combination at concentration 150 $\mu \mathrm{g} / \mathrm{mL}$ that lead to reduction in enzyme levels compared with $\mathrm{CCl} 4$, and then causes hepatoprotection effect.

According to, they found that silymarin is able to decrease injury of liver caused by different agents such as: CCL4, acetaminophen, radiation, overload iron, and finally phenyl hydrazine. Another study indicated that the silymarin has an important role in treatment of hepatotoxicity which is induced by many agents such as: Amanita phalloides, Ethanol, galactosamine, Paracetamol, CCL4, thioacetamide and halothane. So, Silymarin has been used for more than 2000 years to treat hepatic and gallbladder diseases [21].

In the current study we treated the hepatic cell lines with $20 \mathrm{ml}$ of different concentrations of Methotrexate, silymarin and ZN nanoparticles then dissolved in DMSO in addition to the combination of Methotrexate with silymarin or / and ZN nanoparticles. After that incubated at certain atmosphere and humidity, finally we removed the media then adding MTT assay. Apparently, the results showed that the estimated value of IC50 of silymarin and ZN nanoparticles were 270.7 and $93.4 \mathrm{mg} / \mathrm{ml}$ respectively that will be used to evaluate their effect to protect liver from Methotrexate. So, we selected three doses according to the previously dose cell viability curve for silymarin $(100,75$ and $50 \mathrm{mg} / \mathrm{ml})$ and also ZN nanoparticles $(20,10$ and $5 \mathrm{mg} / \mathrm{ml}$ ) to make an evaluation against $75 \mathrm{mg} / \mathrm{ml}$ of Methotrexate so, obviously the results showed that the most hepatoprotective doses exerted by silymarin and ZN nanoparticles were 10 and $50 \mathrm{mg} / \mathrm{ml}$ respectively and also their combination show protective effect to liver against Methotrexate.

There are many studies over the past years which demonstrated that the safety of nanoparticles may also converted into danger which may damage DNA of the cells through generation of oxidative stress via (ROS) reactive oxygen species. This occurs as there is a strong relation between nanoparticles and oxidative stress, so

\section{Virology \& Immunology Journal}

care must be taken about the dose, size particles, and concentration of nanomaterials used [22].

Previous study indicated that zinc oxide nanoparticles causes toxicity to cancer Hep G cells and increases cell viability of Hep G cells. They used $25 \mathrm{~g} / \mathrm{ml} \mathrm{ZnO}$-NPs which exhibited induction of apoptosis, and cytotoxicity in Hep G 2 cells. This cytotoxicity actually occurs due to the generation of oxidative stress and reactive oxygen species. This study also indicated that apoptosis can be enhanced through increasing the concentration of zinc oxide nanoparticles. However treatment of the cells with ZnO-NPs at smaller doses of 5 and $10 \mathrm{~g} / \mathrm{ml}$ did not lead to any change in viability of HepG2 cells. This result was indicated by using MTT assay and RT-PCR results [23].

Another study indicated the cytotoxic effect of zinc oxide nanoparticles in killing tumor cells. They used HepG2 cell lines to prove the toxicity of Zinc oxide nanoparticles. They proved that these metal oxide nanoparticles can kill cancer cells with small effects on the normal cells. They showed that they use nanoparticles in their study due to its great ability to penetrate tumor cells, and causing damage to the DNA of the cells which finally will lead to death of these malignant cells with minimal effect on normal cells. Results of these studies was indicated through using MTT assay technique, and the Cells were exposed to several concentrations of ZnONPs (0, 0.1, 10, 100, $1000 \mu \mathrm{mol} / \mathrm{L})$. This study also determined the concentrations that caused $50 \%$ of maximum inhibition of cell proliferation which called (IC50) via using grApHpAd priSm version 5.0 software .The IC50 value for ZnONPs on HepG2 was 34.67 [24].

According to, $\mathrm{ZnO}$ nanoparticles have apoptotic and genotoxic effect on human liver cells (HepG2) [11]. In their study, they exposed Hep G2 cells to $14-20 \mathrm{Mg} / \mathrm{ml}$ of zinc oxide NPs for $12 \mathrm{hrs}$, and the results showed a reduction in cell viability and death of cells was found to occur due to apoptosis. This toxicity occurs due to DNA damage which was done by oxidative stress Also, Reactive oxygen species lead to reduction in the potential of mitochondria membrane and also act by increasing the ratio of $\mathrm{Bax} / \mathrm{Bcl} 2$ which will lead to mitochondria mediated pathway. This pathway is involved in the process of apoptosis of HepG2cells.

In contrast, there is another study which showed the importance of using zinc oxide nanoparticle to alleviate the cytotoxicity which induced by thioacetamide in vivo. They used zinc oxide nanoparticles of $5 \mathrm{mg}, 7.5 \mathrm{mg}, 10$ $\mathrm{mg} / \mathrm{Kg}$ IP) on rats with injured liver by using 


\section{Virology \& Immunology Journal}

thioacetamide $(100 \mathrm{mg} / \mathrm{Kg})$. Treatment was done three times per week for eight weeks. Using thioacetamide (TAA) leads to increase in levels of liver enzymes (Gamma-glutamyl transferase (GGT), Aspartate aminotransferase (AST), super oxide dismutase (SOD) Alanine aminotransferase (ALT). However, all of these parameters were reduced after treatment with ZnO-NPs. Also, confirmation for the protective effect of zinc oxide nanoparticles was done by using histopathological, and immunohistochemistry studies in the liver, and all results revealed that ZnO-NPs may alleviate the toxicity of TAA through suppression of oxidative stress [25].

According to, Coating of zinc oxide nanoparticles instead of using uncoated zinc oxide nanoparticles will be very helpful in commercial applications where there is human exposure, as these coated nanoparticles showed decrease in cytotoxicity. This occurs as the coating actually will decrease the generation of free radicals. Also, they stated that human hepatic stellate cells (hHSCs) were treated with four types of commercially-available $\mathrm{ZnO}$ nanoparticles suspended in cell culture medium. Two types were with surface coatings, but the other two types were uncoated $\mathrm{ZnO}$ nanoparticles, but with the same size of the coating nanoparticles. Also, all cells were treated with pre-dissolved $\mathrm{ZnSO} 4$ to make a comparison of the responses of the cell to toxicity which induced by ionic zinc. A systems biology approach was used to evaluate the activation of cell signaling pathways, and any changes in the transcriptome or alteration in the cell's function. Assessment was done over $24 \mathrm{hrs}$. Treatment in both types of uncoated zinc oxide nanoparticles lead to death of cells. However both types of surface coating ZnO NPs showed almost complete protection from cytotoxicity which appear from uncoated NPs. Moreover, all cells which were pre-dissolved in $\mathrm{ZnSO}_{4}$, but ionic zinc had little effect on these cells which indicates that cytotoxicity occurrence is mainly due to the nanoparticles.

According to stated that excess free radicals are produced inside the body due to the unbalanced ratio between oxidants and antioxidants which lead to generation of oxidative stress [26]. This unbalanced ratio may be due to normal activities in the body, diseases, or even exposure to toxins. Chemical reaction of toxicity occur due to the attack on phospholipids by the oxygen from hydroxyl radical $(\mathrm{OH})$, then finally form unstable compounds which is called lipid hydroperoxides. In their study, Zinc oxide ( $\mathrm{ZnO})$ nanoparticles was used to form excitonic pair $(\mathrm{e}-, \mathrm{h}+)$ which will act as reactive oxygen species (ROS)scavenger. Assessment for protection against the cell membrane damage was carried out by using lipid peroxidation inhibition assay in liver tissues of rats. Results revealed that a concentration of $600 \mu \mathrm{g} / \mathrm{ml}$ of zinc oxide nanoparticles cause maximum inhibition of lipid peroxidation in liver tissues. So zinc oxide nanoparticles in concentration of $600 \mu \mathrm{g} / \mathrm{ml}$ produce a protective effect in rat's liver tissues.

Another study was carried to prove the great role of zinc oxide nanoparticles to protect liver tissues in rats against the toxicity and injury which induced by dimethylnitrosamine, as dimethylnitrosamine (DMN) is a very potent hepatotoxic compound. This compound actually causes induction of liver cell necrosis and death in experimental animals. Hepatoprotection from zinc oxide nanoparticles is due to Zinc metallothionein ( $\mathrm{Zn}$ MT) which is generated from ZnONPs. Zinc metallothionein causes amelioration of the damage which induced by dimethylnitrosamine. In their study, rats were pretreated with DMN $2 \mu \mathrm{l} / 100 \mathrm{~g}$ body weight to cause induction of liver injuries, and then they were post treated with ZnONPs $50 \mathrm{mg} / \mathrm{kg}$. Zinc oxide nanoparticles were found to reduce lipid peroxidation, fibrosis, necrosis, and oxidative stress. Also it leads to reduction of parameters of the liver eg: serum ALT (alanine transaminases), AST (aspartate transaminases) and LDH (lactate dehydrogenase) which means that there was an improvement in liver function by theses nanoparticles. Histopathological studies also indicated an improvement in the morphology of liver cells [27].

In our study, we used the zinc oxide nanoparticles, and a combination of zinc oxide nanoparticles plus silymarin to produce hepatoprotection against cytotoxicity induced by Methotrexate (MTX) in Hep G2 cell lines. Doses of zinc oxide NPs used were $(20,10$ and $5 \mu \mathrm{g} / \mathrm{ml})$, and silymarin doses were $(100,75$ and $50 \mu \mathrm{g} / \mathrm{ml})$. The most effective dose of zinc oxide nanoparticles alone was $5 \mu \mathrm{g} / \mathrm{ml}$, and this dose actually achieved cell viability of almost $90 \%$ of the cells. Moreover, the most effective dose of both zinc oxide NPs and silymarin was 10 and $50 \mu \mathrm{g} / \mathrm{ml}$ respectively. This combination achieves a great result of hepatoprotection, as it protects about $97 \%$ of Hep G2 cells.

According to, Methotrexate was used in their study to induce cytotoxicity in liver of mice which will be treated then by Sitagliptin (selective dipeptidyl peptidase-4 inhibitor). Results of their study revealed that MTX induced a markable hepatic injury which appears as cloudy swelling, degeneration, apoptosis and necrosis in all hepatic tissues. Also the toxicity of MTX leads to significant increase in levels of serum transaminases, 


\section{Virology \& Immunology Journal}

alkaline phosphatase and lactate dehydrogenase. Moreover, MTX lead to increase in the activation and the expression of nuclear factor kappa-B (NF- $\kappa \mathrm{B})$. Additionally, MTX was found to increase nitrite/nitrate level, and activate inducible nitric oxide synthase (iNOS). All of these will lead to appearance hepatic apoptosis of cells [28].

Another study indicated the cytotoxicity of Methotrexate drug. In this study, they used MTX to induce liver toxicity, and then treatment of liver by turmeric. Their study actually showed a protective effect for groups of rats from MTX by pretreatment with turmeric. When groups of animals which treated by MTX were sacrificed and biomarkers were evaluated, they found a significant increase in serum ALT, AST, ALP and bilirubin. Also, antioxidant defense activities of liver cells were examined by using SOD, CAT, and GSH-Px for the oxidative stress which showed a reduction in antioxidant capacity of liver cells, with clearly damaged liver, while pretreated groups with turmeric showed protection for liver cells.

Another study also demonstrated the toxicity of methotrexate. This cytotoxicity occurs at higher doses such as in case of treatment of cancer diseases. Also, they stated in this study that methotrexate has a lot of side effects at high doses which may be life threatening. In contrast, another study revealed that methotrexate is considered a good drug which is used widely for treatment of many diseases such as multiple sclerosis, dermatomyositis, psoriasis, systemic lupus erythematosus, sarcoidosis, and rheumatoid arthritis. Also, it has been used since 1948 in treatment of acute leukemia in children, and it was approved by the USA Food and Drug Administration (FDA) in 1972 and also in 1988. Additionally, It is one of the most widely used disease anti-rheumatic medicine in the world due to its efficacy, low cost and also because it's very familiar to physicians for a long time. MTX doses are classified as high-dose, intermediate or low-doses. High-doses are used for cancer diseases, and low or intermediate for other diseases such as (RA) rheumatoid arthritis. Dose of MTX for RA is $\left(<50 \mathrm{mg} / \mathrm{m}^{2}\right)$, usually used over long periods of time. Also, in their study, they showed the initial mechanism of MTX as anti-inflammatory drug. It acts by inhibition for dihydrofolate reductase enzyme (DHFR), this will lead to inhibition of the synthesis process of both thymidylate and purine and lead to reduction in the production of DNA and RNA. Also, there are other mechanisms of action were subsequently proposed which is thought to be more accurate. These included that MTX lead to increase in levels of adenosine and inhibition of polyamines, among others. When adenosine level increases, this will exhibit antiinflammatory effects. Previous in vitro studies showed that mice treated with doses of MTX per week lead to an increase in level of adenosine in inflammatory exudates with reduction in accumulation of leukocyte in the inflammatory exudate.

In our study we use MTX drug as a cytotoxic agent to induce toxicity in Hep G2 cells. We use methotrexate dose of $75 \mu \mathrm{g} / \mathrm{ml}$ which actually achieve hepatic dysfunction in HepG2 cells, then hepatoprotective effect of silymarin, and zinc oxide NPs was measured against methotrexate toxicity [29].

\section{Conclusion}

These data suggests that using zinc oxide nanoparticles and silymarin in concentration of 10 and 50 $\mu \mathrm{g} / \mathrm{ml}$ respectively will produce a hepatoprotective effect for large number of Hep G2 cells against the cytotoxic effect of Methotrexate, and this will occur due to the ability of this combination to increase cell viability through lowering the oxidative stress, and improving the antioxidant status of liver cells. This combination may have a great potential for application in future liver disease therapy.

\section{References}

1. Langley L, Telford R, Christensen JB (1980) Dynamic anatomy and physiology, $5^{\text {th }}$ (Edn.), Hill book company, MC graw, New York.

2. American Liver Foundation (2015) Liver awareness month.

3. Byass P (2014) The global burden of liver disease: a challenge for methods and for public health. BMC Med 12: 159 .

4. Ali A Mokdad, Alan D Lopez, Saied Shahraz, Rafael Lozano, Ali H Mokdad, et al. (2014) Liver cirrhosis mortality in 187 countries between 1980 and 2010: a systematic analysis. BMC Medicine journal 12: 145.

5. Geesin JC, Gordon JS, Bergand RA (1990) Retinoids affect collagen synthesis through inhibition of ascorbate-induced lipid peroxidation in cultured human dermal fibroblasts. Arch Biochem Biophys 278(2): 350-355. 


\section{Virology \& Immunology Journal}

6. Jamal Ashraf, Nagma, Jamal Siddique, Nagma Mirani, Abdur Rub (2012) Protective effect of rutin against carbon tetrachloride-induced hepatotoxicity in mice. Int J Drug Dev \& Res 4(2): 352-357.

7. Pandey Govind, Sahni YP (2011) Review on Hepatoprotective Activity of Silymarin. International Journal of Research in Ayurveda and Pharmacy 2(1): 75-79.

8. Sameh S Gad, El Dinshary E, El Bariry A (2015) Effects of Silimarin and Curcumin against LPS-Induced Hepatotoxicity in Rats. British Journal of Pharmacology and Toxicology 6(4): 70-75.

9. Neha, Jaggi AS, Singh N (2016) Silymarin and Its Role in Chronic Diseases. Advances in Experimental Medicine and Biology 929: 25-44.

10. Bektur NE, Sahin E, Baycu C, Unver G (2016) Protective effects of silymarin against acetaminophen-induced hepatotoxicity and nephrotoxicity in mice. Toxicology and Industrial Health 32(4): 589-600.

11. Sharma V, Anderson D, Dhawan A (2012) oxide nanoparticles induce oxidative DNA damage and ROStriggered mitochondria mediated apoptosis in human liver cells (HepG2). Apoptosis 17(8): 852-870.

12. Akhtar MJ, Ahamed M, Kumar S, Khan MM, Ahmad J, et al. (2012) Zinc oxide nanoparticles selectively induce apoptosis in human cancer cells through reactive oxygen species. International Journal of Nanomedicine 7: 845-857.

13. Farideh Namvar, Heshu Sulaiman Rahman, Rosfarizan Mohamad, Susan Azizi, Paridah Mohd Tahir, et al. (2015) Cytotoxic Effects of Biosynthesized Zinc Oxide Nanoparticles on Murine Cell Lines. Evidence-Based Complementary and Alternative Medicine, pp: 11.

14. Boroumand Moghaddam A, Moniri M, Azizi S, Abdul Rahim R, Bin Ariff A, et al. (2017) Eco-Friendly Formulated Zinc Oxide Nanoparticles: Induction of Cell Cycle Arrest and Apoptosis in the MCF-7 Cancer Cell Line. Genes 8(10): 281.

15. Kołodziejczak Radzimska A, Jesionowski T (2014) Zinc Oxide-From Synthesis to Application: A Review. Materials 7(4): 2833-2881.

16. Shen C, James SA, De Jonge MD, Turney TW, Wright PF, et al. (2013) Relating cytotoxicity, zinc ions, and reactive oxygen in $\mathrm{ZnO}$ nanoparticle-exposed human immune cells. Toxicol Sci 136(1): 120-30.

17. Moghadam AR, Tutunchi S, Namvaran Abbas Abad A, Yazdi M, Bonyadi F, et al. (2015) Pre-administration of turmeric prevents methotrexate-induced liver toxicity and oxidative stress. BMC Complementary and Alternative Medicine 15: 246.

18. Emna Gaies, Nadia Jebabli, Sameh Trabelsi, Issam Salouage, Rim Charfi, et al. (2012) Methotrexate Side Effects. Journal of Drug Metabolism \& Toxicology 3: 125.

19. Bath RK, Brar NK, Forouhar FA, Wu GY (2014) Review of methotrexate-associated hepatotoxicity. Journal of Digestive Diseases 15(10): 517-524.

20. LaCasce AS (2014) Therapeutic use and toxicity of high dose methotrexate. In: Maki R, Freedman AS, Pappo AS, Savarese D, (Eds.), Waltham, MA.

21. Faedmaleki F, Shirazi FH, Ejtemaeimehr S, Anjarani S, Salarian AA, et al. (2014) Study of Silymarin and Vitamin E Protective Effects on Silver Nanoparticle Toxicity on Mice Liver Primary Cell Culturez Acta Medica Iranica 54(2): 85-95.

22. Osmond M, Yalchin Oytam, Fariborz Sobhanmanesh, Maxine J McCal, Megan (2014) Surface Coatings Protect against the In vitro Toxicity of Zinc Oxide Nanoparticles in Human Hepatic Stellate Cells. J Nanomed Nanotechnol 5: 232.

23. Rizwan Wahaba, Maqsood A Siddiqui, Quaiser Saquib, Sourabh Dwivedi, Javed Ahmad, et al. (2014) ZnO nanoparticles induced oxidative stress and apoptosis in HepG2 and MCF-7 cancer cells and their antibacterial activity. Colloids and Surfaces B Biointerfaces 117: 267-276.

24. Hassan HF, Mansour AM, Abo Youssef AM, Elsadek BE, Messiha BA (2017) Zinc oxide nanoparticles as a novel anticancer approach; in vitro and in vivo evidence. Clin Exp Pharmacol Physiol 44(2): 235-243.

25. Samir AE Bashandy, Abdulaziz Alaamer, Sherif A Abdelmottaleb Moussa, Enayat A Omara (2017) Role of zinc oxide nanoparticles in alleviating hepatic fibrosis and nephrotoxicity induced by thioacetamide in rats. Canadian Journal of Physiology and Pharmacology 35(10): 1073-1083. 


\section{Virology \& Immunology Journal}

26. Sharda S, Avinash CP, Shashank K, Abhay KP (2014) Cell membrane protective efficacy of $\mathrm{ZnO}$ nanoparticles. Sop Transactions on Nano Technology 1: 810 .

27. Rani V, Verma Y, Rana K, Rana SVS (2017) Zinc oxide nanoparticles inhibit dimethylnitrosamine induced liver injury in rat: Chemico-biological interactions 295: 84-92.

28. Medhat A, Mansour S, El Sonbaty S, Kandil E, Mahmoud M (2017) Evaluation of the antitumor activity of platinum nanoparticles in the treatment of hepatocellular carcinoma induced in rats. Tumor biology 39(7): 1-10.

29. Zakaria ZA, Yahya F, Mamat SS, Mahmood ND, Mohtarrudin N, et al. (2016) Hepatoprotective action of various partitions of methanol extract of Bauhinia purpurea leaves against paracetamol induced liver toxicity: involvement of the antioxidant mechanisms. BMC Complementary and Alternative Medicine 16: 175. 